scarcely producing either impulse, sound, or pulse. Suffocative dyspncea, lividity, and extreme distress, are always concomitant symptoms." So wrote Hope even twenty years ago.

Leeds, Jnly, 1870

\section{FIBROUS TUMOUR OF THE UPPER ARM REMOVED BY OPERATION.}

BX D. HAWLEY B. ANDERSON, M.D., C.M., \&c., ARIIY MEDICAL STAET.

ArIKgL SHaIK, a Moplah, aged thirty, obese but healthy, presented himself with a large swelling on the internal aspect of the upper arm towards its posterior margin, extending from the outer border of the axilla half-way to the elbow-joint. It appeared about the size of a small pineapple, and, from its position, prevented approximation of the arm to the side, the poor fellow holding his elbow out, and his hand depending in an uncomfortable posture. $\mathrm{He}$ had come from his native village, a distance of twenty-four miles, and at his request $\mathrm{I}$ took him in hand.

The swelling, as above described in shape and external situation, had on its most prominent point an ulcerated patch with exuberant granulations, and from this there exuded drops of milky pus. The tumour, on examination, was felt to be globrlar and quite smootb, firm, heavy, and non-elastic, with the skin quite mobile over it, except where adhesive inflarmmation at the sore bound it down to its surface; it moved to a certain extent on the humerus, but not very freely; but whether this was due to the tenseness of the skin over it, or to its having a pedicle attached to the bone or surrounding tissues, was not evident.

The history he gave was: that it commenced spontaneously five years ago as a hard lump; it slowly increased in size until about six months ago, when it was punctured by a native doctor, and some application used, since which time the sore had existed.

The diagnosis was evident enough. The idea of its being a malignant tumour was excluded by the man's general good state of health and absence of glandular enlargements, its slowness of growth, mobility of skin over it, \&e. \&c.

The treatment by excision being therefore determined on, on the morning of the 8th of March the patient was put under the influence of chloroform. I made an incision vertically over the tumour, from the lower border of the axilla for five inches in length, of course cutting through and reflecting off the ulcerating portion of skin without excising it. This incision was subsequently enlarged to the extent of six inches. On cutting through the integuments I came upon a layer of gelatinous-like fibrous tissue, forming a eyst to the denser fibrous structure underneath. I dissected out the tumour, together with this cyst, on its external surface; but on its deeper aspect I found the latter intimately connected with the large nervous cords-one of which was bound down by fibrous bands to the surface of the tumour itself-and also to the muscles. I therefore began to evulse the tumour from its cyst. This was done nearly entirely, some small arteries entering its substance being ligatured; but it was found to be attached still deeper by a pedicle which extended to the periosteum in close relation with the brachial artery, \&c. The vessels and nerves had to be carefully drawn on one side to cut this through. Portions of the cyst were then elipped away, but it was found to blend intimately with the muscular fibres of the triceps. But little blood was lost. Great care was taken in the dissection to keep on the suriace of the tumour itself, otherwise important structures would have been injured. The line of incision luckily just avoided the course of the basilic vein, which was anterior to it at its lower part.

The flaps of skin were approximated by four metallic sutures, pads of lint soaked in carbolic acid and water applied, and bandage.

There was but little constitutional disorder after the operation, and the wound healed up steadily. He has now full use of the arm, though some thickening and induration of the tissues remain. Iodide of potassium, ten grains twice a day, has been administered.
The tumour weighed about a pound. On section, it presented the appearance of dense fibrous tissue; but a large loculus was discovered, which contained broken-down material and pus. On microscopically ezamining it, there was seen true fibrous tissue (nuclei being developed on treating with acetic acid), pus, blood-cells, and coats of bloodvessels.

There is no doubt that the puncture by the native doctor had given rise to softening of the centre of the tumour, which might have caused sloughing out in time.

Malleapoorum, Malabar, Aprii, 18 \%o.

\section{ON M E D I CI N A L P E P I N.}

\section{BY RICHARD V. TUSON, F.C.S.,}

PROFESSOR OF CMEMISTRY AI THE ROIAL TETERINARY COLIEGE, FORMERLY LECTERER ON CHEMISTRT AT THE CFARING-CROSS HOSPITAL.

SINCE the introduction of Corvisart and Boudault's "poudre nutrimentive" into medicine in the year 1854, pepsin obtained from the stomach of the pig, * calf, or sheep, in a state of greater or less impurity, has been extensively prescribed in dyspepsia and certain other affections. According to the testimony of some authorities of high standing, long experience in the use of this agent fully justifies Corvisart's predictions relative to its therapeutic value, which were originally based upon physiological reasoning. There are other authorities, however, equally eminent, who either express doubts as to the efficacy of pepsin, or positively state that it is totally devoid of medicinal power. This difference of opinion, in all probability, mainly arises from the circumstance that pharmaceutists supply medical men with various preparations, all bearing the same specific name of pepsin, but which differ very considerably in their digestive powers and other qualities. In fact, so far as I have at present been enabled to collect evidence relative to the merits and demerits of pepsin, $I$ find those who speak favourably of its employment in the treatment of disease have prescribed that prepared by the best makers; while those who express a doubtful or adverse opinion respecting its value have been in the habit of prescribing those varieties or makes which the experiments of myself and others have proved to be practically without any digestive activity whatever. The relative digesting capabilities of several English and continental pepsins were investigated by Dr. Sievekingt in 1857, and a similar inquiry was conducted by Dr. Pavy* in 1863. The results of the experiments of both gentlemen indicated that there was not mere]y a difference in the qualities of the pepsin prepared by different makers, but that, as was particularly shown by Dr. Pavy, some of the samples examined were totally incapable of digesting muscular tissue. One would have thought that the publicity given to these facts in the medical journals would have caused the prescription of none but the best makes of pepsin, and that it wonld have induced those who had hitherto fabricated an inferior article to have either abandoned its manu facture or to have improved the methods they employed for its preparation. Such, however, is not the case, for pharmaceutists at the present.date continue to vend, and medical men continue to prescribe, both the good and the bad cualities of pepsin. Only a few days ago an old-established and well-known wholesale druggist told me that a customer applied to him for two ounces of pepsin. He asked the customer whose make he required. "The reply was, "the cheapest." On examining the kind of pepsin supplied on this occasion, it was found to be absolutely worthless as regards its power of digestion. Nevertheless it will be used medicinally, and if the patient derives no apparent benefit from its administration, the practitioner who prescribed it may be induced to condemn pepsin in toto; or, should the patient soon get better, the improvement will in all likelihood be attributed to a preparation which is perfectly inert. In the first case, injustice would be done to a medicine which, when properly

* First brought into notice by $D_{r}$. Beale.

+ INedical Times and Gazette, 1557 , vol. i., p. 336 . The Liarcet, April 25th, 1363 